\title{
Two-stage ex-situ catalytic pyrolysis of lignocellulose for the production of gasoline-range chemicals
}

\author{
Devy K. Ratnasari*, Weihong Yang, Pär G. Jönsson \\ KTH-Royal Institute of Technology, Department of Material Science and Engineering, Brinellvägen 23, 10044 Stockholm, Sweden
}

\section{A R T I C L E I N F O}

\section{Keywords:}

Catalytic

Lignocellulosic biomass

Bio-oil

Liquid

Aromatic

\begin{abstract}
A B S T R A C T
The appropriate system is needed to produce a scalable and economically viable renewable energy from biomass. The objective of this study is to improve the quality of bio-oil, in terms of Organic Liquid Product (OLP), water content, acidity, favourable fractions, as well as gasoline-range chemicals. The influence of a staged layered catalyst system consists of a mesoporous catalyst, Al-MCM-41, and a microporous catalyst, HZSM-5, on the biooil quality was investigated. Additionally, the effect of reaction temperatures in the range of $400-600^{\circ} \mathrm{C}$ with the optimum staged catalyst system on the catalytic pyrolysis product was analysed. The experiments of lignocellulosic biomass pyrolysis and catalytic pyrolysis were performed using a fixed bed reactor equipped with oil condensers and a gas collection sample bag. The quality of bio-oil produced from the thermal pyrolysis of lignocellulosic biomass, catalytic pyrolysis with single catalysts, catalytic pyrolysis with the staged catalyst system, as well as catalytic pyrolysis with mixed catalyst system was studied. The results show that Al-MCM-41 with HZSM-5 in the staged catalyst system enhanced the production of favourable compounds: hydrocarbons, phenols, furans, and alcohols. The favourable compounds yield that boosted $5.25-6.43 \%$ of that with single HZSM-5 catalyst was produced with HZSM-5:Al-MCM-41 mass ratio of 3:1 and 7:1. The pyrolysis and catalysis temperature of $500{ }^{\circ} \mathrm{C}$ with HZSM-5:Al-MCM-41 ratio of $3: 1$ obtained the optimum quality of bio-oil with 11.08 wt. $\%$ of OLP, $76.20 \%$ of favourable fractions, 41.97 wt. $\%$ of water content, low TAN of $43.01 \mathrm{mg}-\mathrm{KOH} / \mathrm{g}$, high deoxygenation, as well as high gasoline-range production of $97.89 \%$.
\end{abstract}

\section{Introduction}

The world energy consumption is projected to grow by $56 \%$ between 2010 and 2040 [1]. Despite the various energy carriers, the liquid hydrocarbon still appears to be the primary form of transportation fuel [2]. Thus, the production of liquid fuels from renewable resources is widely recognized as a potential future solution to the increase in energy demands worldwide [3].

Biomass is considered as one of the available sources of carbonbased materials, chemicals, and fuels since it is abundant and represents the cheapest carbon source [4]. However, due to its complex composition [5], the direct use of biomass (e.g. lignocellulose material) as a chemical feedstock faces problems [6]. Therefore, appropriate technologies have been widely investigated to produce a scalable and economically viable renewable energy.

The liquid fuel can be obtained from biomass through thermochemical methods, such as pyrolysis [7] where biomass is decomposed at high temperatures in the absence of oxygen. Besides the liquid phase, known as pyrolysis oil or bio-oil, the pyrolysis results in a solid phase called char and non-condensable gases [8]. The emerging variant of this process, namely the fast pyrolysis process, is characterized by the use of a controlled temperature of around $500{ }^{\circ} \mathrm{C}$, a high heating rate, and a short vapour residence time [9]. The main drawback of a biomass pyrolysis is the high content of water and organic compounds with undesirable properties which lead to low heating values, corrosiveness, and instabilities, often called aging, of the resulting oil [10].

Upgrading the bio-oil can be achieved by introducing catalysts in the pyrolysis process, which can either be done in-situ or ex-situ. Catalytic fast pyrolysis of biomass has been carried out by many researchers since the production of hydrocarbon fuels from biomass is potentially economically attractive [11]. Recent reviews summarize the works [4,12-14].

Among the zeolite catalyst, the most prominent catalyst to produce aromatic hydrocarbons and lighter fractions with a high activity in deoxygenation is an HZSM-5 catalyst. Jae et al. [15] reported that medium pores zeolite, ZSM-5, with pore sizes in the range of 5.2-5.9 led to the highest aromatic yield and the least amount of coke for the conversion of glucose to aromatics in a pyro-probe reactor. However,

\footnotetext{
* Corresponding author.

E-mail address: dkra@kth.se (D.K. Ratnasari).
} 
due to the large molecular size of lignin-derived oxygenates which is considerably larger than the ZSM-5 pore size, the oxygenates cannot enter the pores of ZSM-5 and form coke on its surface. According to an investigation by Yu et al. [16], the large-molecule oxygenates can enter the pores of zeolites when the zeolite was thermally distorted at $650{ }^{\circ} \mathrm{C}$, which enlarged the pore size of zeolite by $2.5-3.4 \AA$.

The mesoporous catalyst, Al-MCM-41, which has larger pore size than ZSM-5, in the range of 30-40 $\AA$ [6,17-20], has the ability to crack large molecules, to be less prone to deactivation, and to give higher yields of OLP which contains aliphatic hydrocarbons. In addition, the Al-MCM-41 appears to eliminate completely levoglucosan [2,6,21-23].

Each mentioned catalysts, HZSM-5 and Al-MCM-41, have high potential in converting biomass into desirable chemicals with high selectivity and yield as well as low coke formation. It is possible to improve or alter the OLP composition through a cascade system of the mesoporous and microporous catalyst. There have been several studies in the literature reporting the bio-oil upgrading through a cascade system of catalysts.

Marker et al. [24] recovered $30 \mathrm{wt} . \%$ of gasoline and $8 \mathrm{wt} . \%$ of diesel from catalytic hydrocracking of lignin with combined zeolite and amorphous silica-alumina catalyst at a temperature between 340 and $435{ }^{\circ} \mathrm{C}$ under a pressure about $3.4 \mathrm{MPa}$ to about $12 \mathrm{MPa}$. In the Fluid Catalytic Cracking (FCC) process, zeolite $\mathrm{Y}$ and silica-alumina $\left(\mathrm{SiO}_{2}-\right.$ $\mathrm{Al}_{2} \mathrm{O}_{3}$ ) are utilized to produce a high gasoline yield.

In 1996, Adjaye et al. [25] investigated the upgrading of biofuels from a rapid thermal processing of maple wood when using silica-alumina and HZSM- 5 catalysts in a fixed-bed micro-reactor at a temperature of $370^{\circ} \mathrm{C}$. Their results showed that it is possible to change the hydrocarbon distribution in the Oil Liquid Product (OLP) fraction by physically mixing catalysts with different functionalities. Silica-alumina produced an OLP fraction which mostly of aliphatic hydrocarbons. By gradually increasing the amount of HZSM-5 in the catalyst mixture, the content of OLP gradually changed from predominantly aliphatic to a mixture of aliphatic and aromatic hydrocarbons. When the HZSM-5 content was increased, in the range between 13 and $27 \mathrm{wt} . \%$ of the biofuel feed, the yield of OLP was also rose. The main product was aliphatic hydrocarbons (37-77 wt.\% of OLP), followed by aromatic hydrocarbons (2-38 wt.\% of OLP).

A study by Zhang et al. [26] examined the effect of adding mesoporous and macroporous catalyst (Gamma-Al2O3, $\mathrm{CaO}$, and MCM-41) in the microporous catalyst (LOSA-1) by physically mixing the catalysts for the catalytic pyrolysis of rice stalk in an internally interconnected fluidized bed. Compared to using a single LOSA-1 catalyst, the maximum aromatic and olefin yield of $25.3 \%$ was obtained with $10 \%$ Gamma- $\mathrm{Al}_{2} \mathrm{O}_{3} / 90 \%$ LOSA-1 [26].

Zhang et al. [27] also point towards improving the aromatics yield by adding meso- and macroporous catalysts ( $\mathrm{CaO}, \mathrm{MgO}$, and FCC) in a microporous catalyst (ZSM-5). They performed and analysed a catalytic pyrolysis of pine wood with two catalysts using ThermogravimetryFourier Transform Infrared Spectroscopy (TG-FTIR) and Pyrolysis-Gas Chromatography/Mass Spectrometry (Py-GC/MS). The maximum aromatic yield which was $30 \mathrm{wt} . \%$ higher than that with pure ZSM-5 was obtained with a biomass/CaO/ZSM- 5 mass ratio of 1:4:4 in a separate mode of feedstock, $\mathrm{CaO}$, and ZSM- 5 inside a quartz filler tube.

The present study considers using a staged mesoporous and microporous catalyst to enhance the bio-oil quality, as seen in Fig. 1. By employing mesoporous catalyst, Al-MCM-41, and microporous catalyst, HZSM-5, in staged layers, and considering a continuous flow of carrier gas, the pyrolysis vapour is constrained to pass through a layer of catalyst one after another. This system will ensure the large molecule oxygenates will be cracked into small molecule oxygenates through Al-MCM-41 before entering HZSM- 5 pores. In case of using physically mixing catalyst, there may be no certain path whether the pyrolysis vapour firstly passes through Al-MCM-41 or directly enters the pores of HZSM-5. A bench-scale experiment using a fixed bed reactor has been carried out to investigate the effect of a staged layered

\section{Biomass}

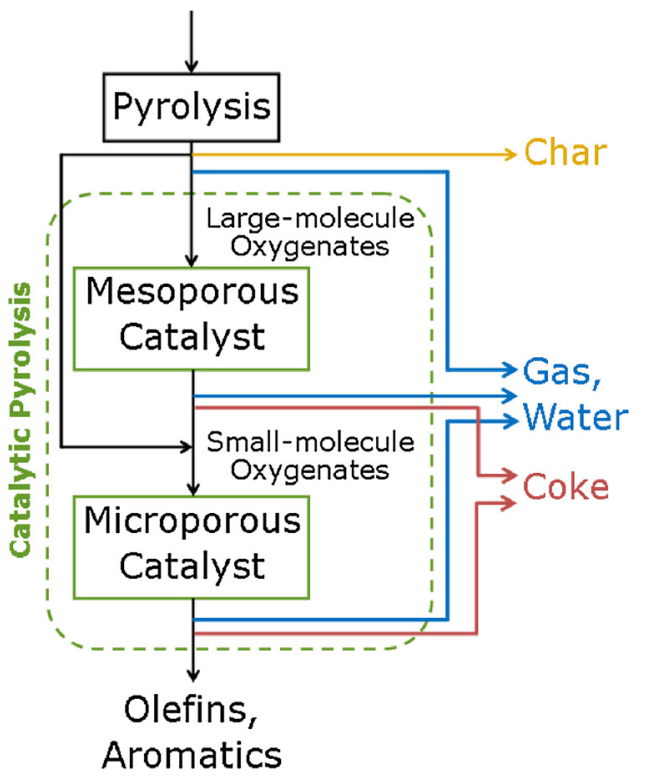

Fig. 1. Catalytic pyrolysis of biomass with mesoporous and microporous catalyst. (adapted from Zhang et al. [21]).

catalyst system on the bio-oil quality in a large scale compared to using Py-GC/MS.

Recent work by Author et al. [28] obtained positive results on upgrading waste plastics to produce gasoline-range hydrocarbons by using Al-MCM-41 and ZSM-5 zeolite catalysts in a staged layered catalyst system. The results showed that using the staged catalysis a high yield of oil product (83.15 wt.\%) was obtained from high-density polyethylene at an Al-MCM-41:ZSM-5 ratio of $1: 1$. The oil product was highly aromatic $(95.85 \mathrm{wt} . \%$ of oil) consisting of $97.72 \mathrm{wt} . \%$ of gasoline range hydrocarbons. Later in this study, the results revealed that the bio-oil was also in the range of gasoline chemicals.

Accordingly, the objective of this work is to improve the quality of bio-oil, in terms of OLP, water content, acidity, favourable fractions, as well as gasoline-range chemicals, in lignocellulosic biomass catalytic pyrolysis by using staged-catalysts of HZSM-5 and Al-MCM-41. Nevertheless, enhancing the yield of bio-oil was examined. The effect of the physically mixing of the Al-MCM-41 with HZSM-5 zeolite catalyst on the products was also evaluated. Furthermore, the influence of the temperature on the composition of the oils and gases during the staged catalyst pyrolysis of biomass was observed.

\section{Materials and methods}

\subsection{Materials}

Lignocellulosic biomass from beech wood was provided by $\mathrm{J}$. Rettenmaier \& Söhne GMBH + CO KG, Rosenberg. For the catalytic pyrolysis experiments, the sample had a particle size ranging from $300 \mu \mathrm{m}$ to $500 \mu \mathrm{m}$. Before an experiment, the sample was dried in an oven at $110^{\circ} \mathrm{C}$ overnight to reduce the water content [29]. The proximate and ultimate analysis is shown in Table 1.

Catalysts in the powder form of Al-MCM-41 and HZSM- 5 were obtained from Nankai University Catalyst Plant in China and Alfa Aesar in Germany, respectively. Prior to catalytic pyrolysis experiments, the catalysts were calcined in a muffle furnace at $550{ }^{\circ} \mathrm{C}$ for $15 \mathrm{~h}$ and dried in an oven at $110^{\circ} \mathrm{C}$ for $12 \mathrm{~h}$.

Table 2 shows the properties of the catalysts. 
Table 1

Properties of the Lignocellulosic Biomass used for Catalytic Pyrolysis Experiments on Dry Basis.

\begin{tabular}{lll}
\hline Proximate analysis (wt.\%) & & \\
\hline Volatiles, db & 84.2 & SS-EN ISO 18123:2015 \\
Moisture, $105^{\circ} \mathrm{C}$ & 14.1 & SS-EN ISO 18134-1:2015/-2:2017 \\
Ash, $550^{\circ} \mathrm{C} \mathrm{db}$ & 0.8 & SS-EN ISO 18122:2015 \\
Fixed carbon & 0.9 & Calculated \\
\hline
\end{tabular}

Ultimate analysis (wt.\%)

\begin{tabular}{lll}
\hline Carbon (C), db & 49.1 & SS-EN ISO 16948:2015 \\
Hydrogen (H), db & 6.1 & SS-EN ISO 16948:2015 \\
Oxygen (O), db & 43.8 & Calculated \\
Nitrogen (N), db & 0.12 & SS-EN ISO 16948:2015 \\
Sulphur (S), db & 0.026 & SS-EN ISO 16948:2015 \\
\hline
\end{tabular}

$\mathrm{db}=$ dry basis.

Table 2

Properties of the Catalysts.

\begin{tabular}{llll}
\hline Catalyst & Si:Al ratio (SAR) & $\begin{array}{l}\text { BET Surface Area } \\
\left(\mathrm{m}^{2} \mathrm{~g}^{-1}\right)\end{array}$ & $\begin{array}{l}\text { Micropore Volume } \\
\left(\mathrm{cm}^{3} \mathrm{~g}^{-1}\right)\end{array}$ \\
\hline HZSM-5 & 30 & 314.7320 & 0.1492 \\
Al-MCM-41 & 25 & 957.5100 & - \\
\hline
\end{tabular}

\subsection{Experimental reactor}

The catalytic fast pyrolysis reactor system was made up of a fixed bed reactor equipped with oil condensers and a gas collection sample bag (Fig. 2). Initially, the reactor was heated up to the chosen temperature for the experiment. After the temperature in the furnace

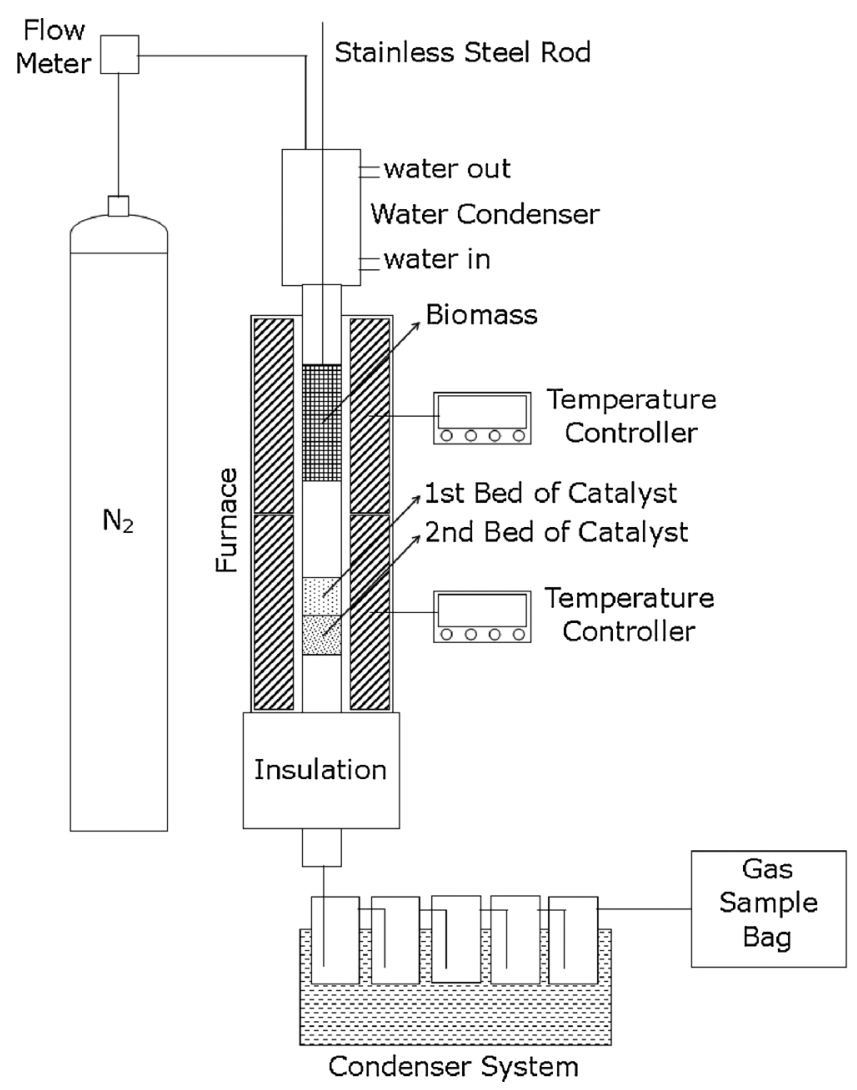

Fig. 2. Schematic Diagram of the Two-Stage Catalytic Pyrolysis Reactor. reached the desired level, a stainless steel rod enabled to push a movable crucible containing the unreacted biomass from the water condenser tube to the middle of the furnace. The pyrolysis and catalysis both underwent the same temperature profile. The evolved volatiles from the sample ( $10 \mathrm{~g}$ ) was passed directly to the ex-situ beds containing catalysts which had been previously heated. The thermal pyrolysis, as well as catalytic pyrolysis with staged catalysts and mixed catalysts, were conducted at a temperature of $500{ }^{\circ} \mathrm{C}$. Further, catalytic pyrolysis with staged catalysts was examined at 400 and $600{ }^{\circ} \mathrm{C}$ to investigate the influence of temperature on the bio-oil quality. The ratio of Al-MCM-41 and HZSM- 5 zeolite catalyst was altered to give the required ratio whilst always maintaining a catalyst bed mass of $20 \mathrm{~g}$. The ratio of sample to catalysts was $1: 2$. Also, nitrogen was used as the carrier gas to provide an inert atmosphere and to carry the product gases through the reactor. For a typical run, after lignocellulosic biomass was fed to the reactor, the catalytic pyrolysis process was carried out for $30 \mathrm{~min}$. Thereafter, the crucible containing the reacted biomass was pulled-out from the middle of furnace back to the water condenser tube by using a stainless steel rod, following a purge of the reactor with $350 \mathrm{ml} \mathrm{min}{ }^{-1}$ of nitrogen for another $15 \mathrm{~min}$ at the reaction temperature to strip any remaining product from the catalyst.

The condensable liquid products were collected by five condensers maintained at $-15{ }^{\circ} \mathrm{C}$ by isopropanol bath. The condenser system was connected to a Tedlar ${ }^{T M}$ gas sample bag to enable a collection of noncondensable gases. After the experiments, the condensers were immediately sealed to prevent an evaporation of highly volatile products. Furthermore, the condensers were weighted to determine the total liquid yield. The mass balance was obtained by weighing the sample basket, catalysts and the condensers before and after experiments. The mass of gas was calculated from the gas chromatography data and the flow of gases related to the flow rate of nitrogen purge gas and gas concentration in the gas sample bag.

The catalytic pyrolysis experiments were replicated at least three times to verify the reproducibility of the data. The precisions of each analysis were expressed as a 95\% Confidence Interval (CI). Data acquisition and data processing were carried out using Analysis ToolPak, an add-in program in Microsoft Excel.

\subsection{Product analysis}

The liquid was analysed using an Agilent 7890 A gas chromatography coupled to an Agilent 5975C mass spectrometer, which served to identify the compounds present in the liquid. The GC column was made up of a $60 \mathrm{~m}$ x $0.250 \mathrm{~mm} \times 0.25 \mu \mathrm{m}$ HP-5MS capillary column. The NIST11 library was used to identify the components enabling classification of the oils based on their gasoline-range (C5-C12) and high molecular weight (> C12) contents. The data presented was based on peak areas.

The water content of liquid products was determined using a Mettler-Toledo volumetric Karl-Fischer titrator T5 [30]. Total Acid Number (TAN) of the liquid products was determined by titrating biooil solution in methanol with $\mathrm{KOH}$ solution in methanol of known concentration [31].

The liquid products from pyrolysis and catalytic pyrolysis of lignocellulosic biomass were shaken/stirred vigorously to produce a homogeneous mixture before the analysis using GC-MS and MettlerToledo volumetric Karl-Fischer.

Gases collected in the Tedlar ${ }^{T M}$ gas sample bag were analysed immediately after each experiment by using an Agilent 490-micro-Gas Chromatograph (GC). The mass of gas was calculated from the gas chromatography data and the flow of gases related to the flow rate of nitrogen purge gas and gas concentration in the gas sample bag.

There was no considerable change in the char composition since there was no physically mixing of biomass and catalysts and considered as ex-situ systems. 
Table 3

Product yields (wt.\%) from catalytic pyrolysis of lignocellulosic biomass over different systems with 95\% mean Confidence Intervals (CIs).

\begin{tabular}{|c|c|c|c|c|c|}
\hline \multirow[t]{2}{*}{ System } & \multicolumn{4}{|l|}{ Product yield } & \multirow[t]{2}{*}{ Mass Balance } \\
\hline & Oil & Water & Gas & Char & \\
\hline No Catalyst & $28.43 \pm 0.01$ & $28.87 \pm 0.01$ & $11.93 \pm 0.02$ & $30.77 \pm 0.02$ & $98.74 \pm 0.02$ \\
\hline HZSM-5 & $9.07 \pm 0.01$ & $43.09 \pm 0.02$ & $22.34 \pm 0.02$ & $25.50 \pm 0.02$ & $93.75 \pm 0.03$ \\
\hline Al-MCM-41 & $23.37 \pm 0.02$ & $31.92 \pm 0.02$ & $18.11 \pm 0.04$ & $26.60 \pm 0.05$ & $99.06 \pm 0.03$ \\
\hline \multicolumn{6}{|c|}{$\begin{array}{l}\text { Staged-Catalyst } \\
\text { (HZSM-5:Al-MCM-41) }\end{array}$} \\
\hline $7: 1$ & $9.97 \pm 0.01$ & $42.11 \pm 0.03$ & $22.16 \pm 0.05$ & $25.76 \pm 0.01$ & $95.25 \pm 0.04$ \\
\hline $3: 1$ & $10.31 \pm 0.01$ & $41.58 \pm 0.03$ & $22.19 \pm 0.04$ & $25.92 \pm 0.04$ & $90.95 \pm 0.03$ \\
\hline $1: 1$ & $14.51 \pm 0.01$ & $38.83 \pm 0.02$ & $20.85 \pm 0.05$ & $25.80 \pm 0.01$ & $92.05 \pm 0.02$ \\
\hline $1: 3$ & $20.76 \pm 0.01$ & $33.25 \pm 0.02$ & $20.28 \pm 0.02$ & $25.71 \pm 0.04$ & $98.00 \pm 0.02$ \\
\hline \multicolumn{6}{|c|}{$\begin{array}{l}\text { Mixed-Catalyst } \\
\text { (HZSM-5:Al-MCM-41) }\end{array}$} \\
\hline $7: 1$ & $14.21 \pm 0.01$ & $39.38 \pm 0.01$ & $21.73 \pm 0.03$ & $24.69 \pm 0.04$ & $95.39 \pm 0.01$ \\
\hline $3: 1$ & $15.23 \pm 0.01$ & $38.32 \pm 0.01$ & $21.88 \pm 0.02$ & $24.57 \pm 0.03$ & $98.97 \pm 0.02$ \\
\hline $1: 1$ & $19.67 \pm 0.01$ & $34.22 \pm 0.02$ & $21.23 \pm 0.02$ & $24.88 \pm 0.01$ & $98.18 \pm 0.04$ \\
\hline $1: 3$ & $21.36 \pm 0.01$ & $32.83 \pm 0.01$ & $20.33 \pm 0.03$ & $25.48 \pm 0.04$ & $94.73 \pm 0.02$ \\
\hline
\end{tabular}

\section{Results and discussion}

\subsection{Comparison between staged-catalysts and physically mixed-catalysts consisting of HZSM-5/Al-MCM-41}

The mesoporous Al-MCM-41 and microporous HZSM-5 catalysts in the stage-layered system were used to produce oil rich in gasoline-range chemicals (C5-C12) from the catalytic pyrolysis of lignocellulosic biomass at a temperature of $500{ }^{\circ} \mathrm{C} \mathrm{A}$ comparison was made with catalytic pyrolysis of lignocellulosic biomass using physically mixed of HZSM-5 and Al-MCM-41. For all these experiments, the ratios of HZSM-5 and AlMCM-41 used for the catalytic pyrolysis process were $7: 1,3: 1,1: 1$, and $1: 3$.

\subsubsection{Product yield}

Table 3 shows the product yields from catalytic pyrolysis of lignocellulosic biomass over different systems with 95\% mean Confidence Intervals (CIs). In general, the repeatability of the catalytic pyrolysis systems was shown by more than $90 \%$ of the mass balance in most of the cases. The measurements for each case were found to be statistically identical. The significant differences in the production of oil, water, gas, and char were also encountered among all systems, apart from the oil and gas yields from the experiments with HZSM-5:Al-MCM-41 ratio of 7:1 and 3:1, both in staged-catalyst and mixed-catalyst systems. During the catalytic experiments, the reproducibility of the experimental data is calculated to be within $\pm 5 \%$ with a $95 \%$ CI.

The liquid from the pyrolysis of lignocellulosic biomass was a homogeneous and single phase. However, two phases of bio-oil (aqueous and oil phases) were observed after the pyrolysis vapours were passed over the catalyst bed. This is due to the significant amount of hydrocarbons, mainly aromatics, in the oil phase. The highest yield of oil, also known as OLP, was obtained in the thermal processing or noncatalytic system of lignocellulosic biomass, amounting to $28.43 \mathrm{wt}$.\%. In catalytic runs, Al-MCM-41 led pyrolysis vapours mainly to OLP with the yield of 23.37 wt.\%, compared to single HZSM-5 and catalysts with HZSM-5 contents.

The application of HZSM-5 decreased the OLP due to the increased production of non-condensable gases. As seen in Table 3, the gas yield increased with increasing HZSM-5 content, either in staged-catalysts or mixed-catalysts. The present finding also supports Imran et al. [32] study. They investigated catalytic flash pyrolysis of biomass using different types of zeolite. They reported that the catalytic pyrolysis of lignocellulosic biomass using zeolite catalysts produced 9-23 wt.\% of OLP, while thermal processing of biomass resulted in OLP of $46 \mathrm{wt} . \%$. The high content of HZSM-5 with a catalyst/biomass ratio of $1: 1$ also increased the gas fraction from $11.6 \%$ to $46.8 \%$ compared to the non- catalytic experiment [32]. Atutxa et al. [33], Du et al. [34], and Zhang et al. [35] also found that the presence of HZSM-5 promoted the transformation of heavy liquid fraction into light liquid fraction and gases that led to an increase of gas yields and a decrease of OLP, which was consistent with the finding of this study.

Interestingly, the oil yields in staged-catalysts systems were lower than the yields in mixed-catalysts systems, while for the gas yields, the staged-catalysts systems produced more gaseous products than the mixed-catalysts systems. This finding suggested that the deoxygenation and secondary cracking reaction of the product vapours were effectively occurred in staged-catalysts systems, when the large-molecule oxygenates from pyrolysis vapours were broken down into small-molecule oxygenates with Al-MCM-41 catalyst, which was employed as the first layer of staged-catalyst, before passing through HZSM-5 catalysts as the second layer of staged-catalyst.

The finding also revealed that the high production of OLP along with the low formation of gaseous products in the mixed-catalysts systems has been linked to the influence of Al-MCM-41 and HZSM-5 pore sizes. Since the pore size of Al-MCM-41 is larger than HZSM- 5 pore size, the oxygenate-molecules easily entered the pore of Al-MCM-41 compared to the HZSM-5 pores. Alternatively, by physically mixing the catalysts, there was no certain pathway for the oxygenate molecules to enter HZSM-5 pores after Al-MCM-41 pores. Due to the large pore size of Al-MCM-41, the oxygenate-molecules were assumed to preferably enter Al-MCM-41 pores. Thus, the presence of Al-MCM-41 in the mixedcatalyst more highly affected the product yields in mixed-catalyst systems.

Table 4 also shows that gas composition from pyrolysis and catalytic pyrolysis of lignocellulosic biomass with staged-catalysts and mixed-catalysts. The marked increase in gas yield mainly due to the increase in $\mathrm{CO}$ and $\mathrm{CO}_{2}$. The hydrogen and hydrocarbon gases decreased as the composition of HZSM-5 either in staged-catalysts or mixed-catalysts increased. The finding also revealed that the oxygen species are converted to $\mathrm{CO}$ and $\mathrm{CO}_{2}$ in catalytic pyrolysis of lignocellulosic biomass with HZSM-5. Therefore, the yields of CO and CO2 gases increased with the increasing composition of HZSM-5 in staged- and mixed- catalyst.

Non-catalytic process obtained $28.87 \mathrm{wt}$ \% of water content without phase separation. After the addition of catalysts, the water content increased. This finding provides evidence that the pyrolysis oil was highly viscous, while the bio-oil obtained via catalytic pyrolysis was less viscous. Obviously, the large-molecule oxygenates were cracked to lighter fractions and gaseous components in catalytic pyrolysis. The highest water content of 43.09 wt.\% was observed in the catalytic pyrolysis of lignocellulosic biomass with HZSM-5 catalyst. This is due to a large number of microspores which were beneficial to convert hydrogen and 
oxygen as well as pyrolysis vapours into water [26,36]. Therefore, as seen in

Table 3, the water content increased as the proportion of HZSM-5 increased, either in staged-catalysts systems or mixed-catalysts systems.

Compared to the runs with single HZSM-5 or catalyst systems with HZSM-5 contents, catalytic pyrolysis of lignocellulosic biomass with AlMCM-41 produced low water content, which indicates a weak dehydration activity. Due to the high influence of Al-MCM-41 catalyst in mixed-catalysts systems, the low water contents were observed in mixed-catalysts systems compared to those in staged-catalysts systems. For example, with the HZSM-5 and Al-MCM-41 ratio of 3:1, the water content in the mixed-catalysts system was $38.32 \mathrm{wt} \%$, while it was $41.58 \mathrm{wt} . \%$ in the staged-catalysts system.

The effect of HZSM-5 on the water content in the present study is consistent with the findings of past studies by Samolada, et al. [37], which examined the conversion of representative bio-oil model compounds over different catalytic materials and concluded that the HZSM5 zeolite completely converted unfavourable carbonyls to hydrocarbons with a simultaneous loss of the organic liquid fraction and a dramatic increase of $\mathrm{H}_{2} \mathrm{O}$. Another investigation by Zhang et al. [35] found that the presence of HZSM-5 in catalytic pyrolysis of corncob at $400-700{ }^{\circ} \mathrm{C}$ in fluidized bed reactor increased the yields to water and non-condensable gas, while decreased the liquid yields, which is in good agreement with the results of the present study.

The acidity of the bio-oils was expressed by the TAN, analogous to the commercially accepted use of TAN values for petroleum feedstock. Fig. 3 shows the Total Acid Number (TAN) of the bio-oils for all systems. TAN of bio-oil from the non-catalytic experiment was $155.26 \mathrm{mg}$ $\mathrm{KOH} / \mathrm{g}$. It increased when single Al-MCM-41 and ratio HZSM-5:AlMCM-41 of 1:3, either staged-catalyst or mixed-catalyst system, were employed in the catalytic pyrolysis process. However, when the proportion of HZSM-5 in the catalyst systems was increased, the TAN of bio-oil decreased and reached the lowest point of $19.60 \mathrm{mg}-\mathrm{KOH} / \mathrm{g}$ with the single HZSM-5 catalyst.

On the other hand, as seen in Table 5 the acids and carbonyls (such as aldehydes and ketones) increased with the adding of Al-MCM-41 in the catalysts systems. In the non-catalytic run, acids, aldehydes, and ketones amounted to $15.13,19.77$, and $11.94 \%$, respectively, while they were $15.63,20.21$, and $19.54 \%$, respectively, in catalytic pyrolysis with single Al-MCM-41. This study indicates that acids and carbonyls affect the acidity of bio-oil.

The present finding also supports Wang et al. [38] study which concludes that TAN is correlated with the presence of naphthenic acid in the oil. The increasing content of acids in the oil led to the rising of TAN. Wang et al. [38] found TAN of oil with $61.7 \%$ of naphthenic acid was $95 \mathrm{mg} \mathrm{KOH} / \mathrm{g}$, while it was $149 \mathrm{mg} \mathrm{KOH} / \mathrm{g}$ with $96.7 \%$ of naphthenic acid.

Though acids and carbonyls content in the bio-oils from both staged-catalyst and mixed-catalyst systems with ratio HZSM-5:Al-MCM41 of 1:3 were lower than the content from the single Al-MCM-41 run, the TANs were even higher than those from the single Al-MCM-41 experiment. This is due to the correlation between the yield of acids and other groups of compounds in bio-oils, such as oxygenate molecule or sugar fraction. Compounds with high pKa values may highly affect TAN, even though their presence was small.

The finding is consistent with findings of past studies by Moens et al. [39] who studied neutralization and stabilization of fast pyrolysis biooils and used the TAN as an indication of the change in acidity. They indicate that the TAN of bio-oil is related to carbonyls contents, which mentioned by Wang et al. [38] as naphthenic acid.

Oasmaa and Czernic [40] revealed that acids and sugar fractions are the main factors for causing acidity of bio-oils, which is in good agreement with the results of the present study. A good correlation of the yield of acids and oxygen content in bio-oil with the TAN is derived mainly (60-70\%) from the volatile acids, whose pKa values are the lowest of all of the compounds in bio-oil. There are also other groups of 


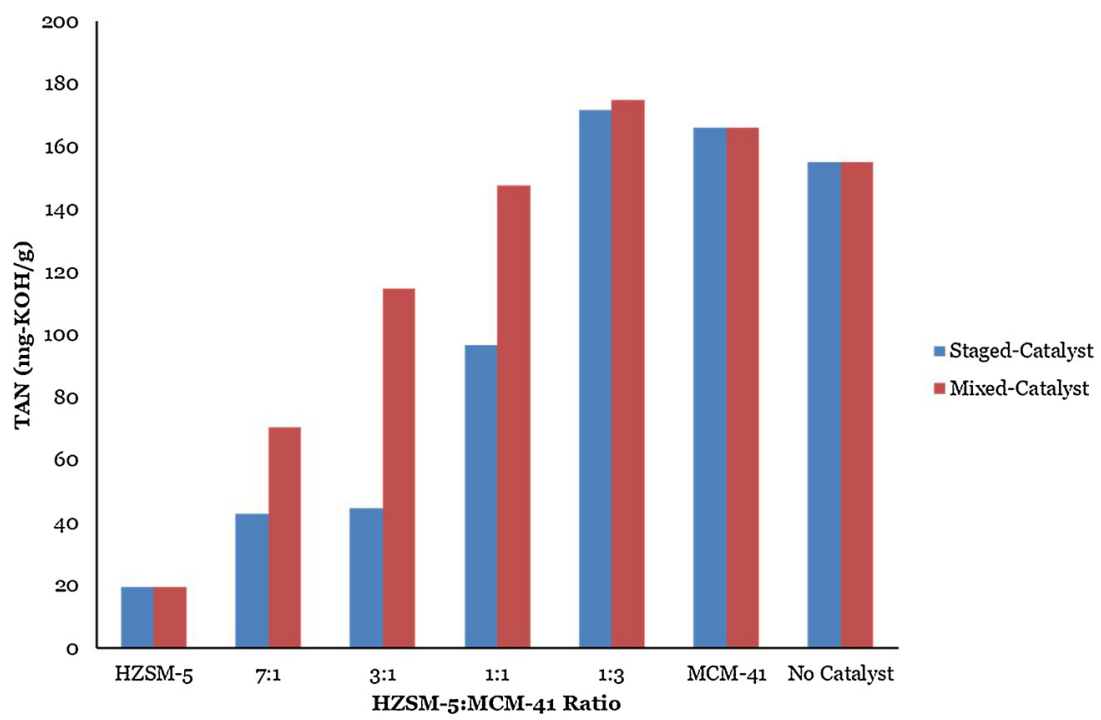

Fig. 3. Total Acid Number (TAN) in the bio-oils from pyrolysis and catalytic pyrolysis of. lignocellulosic biomass.

compounds in fast pyrolysis bio-oils that influence acidity, such as phenolic $(5-10 \%)$ and fatty and resin acids $(<5 \%)$. The acidity of the 'sugar' fraction, mainly because of hydroxy acids, covers about $20 \%$ of the total acidity [41].

The TAN requirement for upgraded bio-oil to be compatible with a petroleum refinery infrastructure was a value of 1 or less [39]. Unfortunately, TAN from this study was still too high for further processing in a petroleum refinery.

\subsubsection{Analysis of the pyrolysis and catalytic pyrolysis oil}

Consistent with findings by Mullen and Boateng [42], we found that the HZSM- 5 catalyst gave the highest yields of aromatics of $91.75 \%$, as seen in Table 5 . In the catalytic pyrolysis systems, both staged-catalysts and mixed-catalysts, the proportion of HZSM- 5 affected the yield of aromatics. The more HZSM-5 in the catalysts systems, the more aromatics produced. The enhanced depolymerisation likely occurred to convert aliphatic linkers of phenolic units to olefins and then to aromatic compounds by aromatization [42].

Pattiya et al. [43] investigated the upgrading of the vapours from the pyrolysis of cassava rhizome in a pyrolysis-gas chromatographymass spectrometry (Py-GC-MS) system using various catalysts. They concluded that the ZSM- 5 catalyst was the most active catalyst and increased the formation of aromatic hydrocarbons and decreased oxygenated lignin-derived compounds and carbonyls [43], which is in good agreement with the results of the present study.

The OLP from catalytic pyrolysis systems, either staged-catalysts or mixed-catalysts systems, which consisted mostly of aromatics hydrocarbons due to the addition of HZSM- 5 in the catalysts systems from the present study agrees relatively well with that from Adjaye et al. [25]. They studied the effect of mixtures of HZSM- 5 and silica-alumina on the product distribution during the conversion of maple wood to bio-oil and observed that the gradual increase of HZSM5 in the mixture changed the hydrocarbon products from aliphatic to aromatic. However, in the present study, staged-catalysts systems were more effective to produce aromatics than mixed-catalysts systems since in the staged-catalysts systems, the pyrolysis vapour was directed to pass through Al-MCM-41 layer before the oxygenates being cracked in the HZSM-5 layer, whereas there were no certain pathways for the pyrolysis vapour cracking in the mixed-catalysts systems.

The oxygenate contents decreased steadily when HZSM-5 was adding to the catalysts systems, either staged-catalysts or mixed-catalysts systems. It decreased to $6.05 \%$ from $94.23 \%$ in the non-catalytic oil. The remarkable increase was observed in aromatic compounds when using HZSM-5, which was consistent with the finding of Zhang et al. [35]. By increasing the proportion of HZSM-5 in the catalysts systems, the amount of acid and ketone decreased compared to the pyrolysis oil, which was good for improving the quality of the oil.

On the other hand, the use of Al-MCM-41 enhanced the formation of phenols as favourable fractions. Rising the proportion of Al-MCM-41 in the catalysts systems promoted the increasing of phenols. The present finding agrees relatively well with Antonakou et al. [6]. They found that Al-MCM-41 with Si/Al ratio (SAR) of 20 led to the production of phenols. Adam et al. [44] tested Al-MCM-41 for catalytic pyrolysis of spruce wood in Py-GC/MS with biomass/catalyst ratio of 1:1 at a temperature of $500{ }^{\circ} \mathrm{C}$ to improve the quality of bio-oil in terms of phenol yields. The results showed that there was an increase in phenols yields, which is in good agreement with the result of the present study. However, the large pore of the Al-MCM- 41 seemed to have a deteriorating effect on the quality of the bio-oil. The acids and carbonyls (such as aldehydes and ketones) increased with the adding of Al-MCM41 in the catalysts systems.

To simplify the results of oil analysis, the products were grouped into favourable and unfavourable product groups. Hydrocarbons and phenols are considered to be the favourable fractions due to their high commercial value. Additionally, furans and alcohols are also classified as favourable compounds since furans are stable compounds with high energy value and alcohols are considered as fuels. Contrarily, oxygenate compounds, such as acids, carbonyls, and Polycyclic Aromatic Hydrocarbons (PAHs) are unfavourable compounds among the pyrolysis and catalytic pyrolysis products.

As shown in Table 6, all runs with catalysts reduced the amounts of unfavourable compounds, while more favourable compounds were obtained. The non-catalytic system produced $25.25 \%$ of favourable compounds, while single Al-MCM-41 and HZSM-5 resulted in $30.05 \%$ and $70.93 \%$ of them, respectively. Both staged-catalysts and mixedcatalysts systems showed similar trends and obtained more favourable compounds in most cases compared to single catalyst systems. The yield of favourable products increased by adding high content of HZSM-5 in the catalysts systems. This was an evidence that HZSM- 5 is effective in deoxygenation reactions and successful in enhancing the yields of the favourable compounds and reducing the undesired compounds in the bio-oil.

Interestingly, it is revealed from Table 6 that the favourable compound resulted from catalytic pyrolysis using the mixed-catalyst system with HZSM-5:Al-MCM-41 ratio of 7:1 was $4.67 \%$ higher than it from catalytic pyrolysis using single HZSM-5. Similar trends were observed 


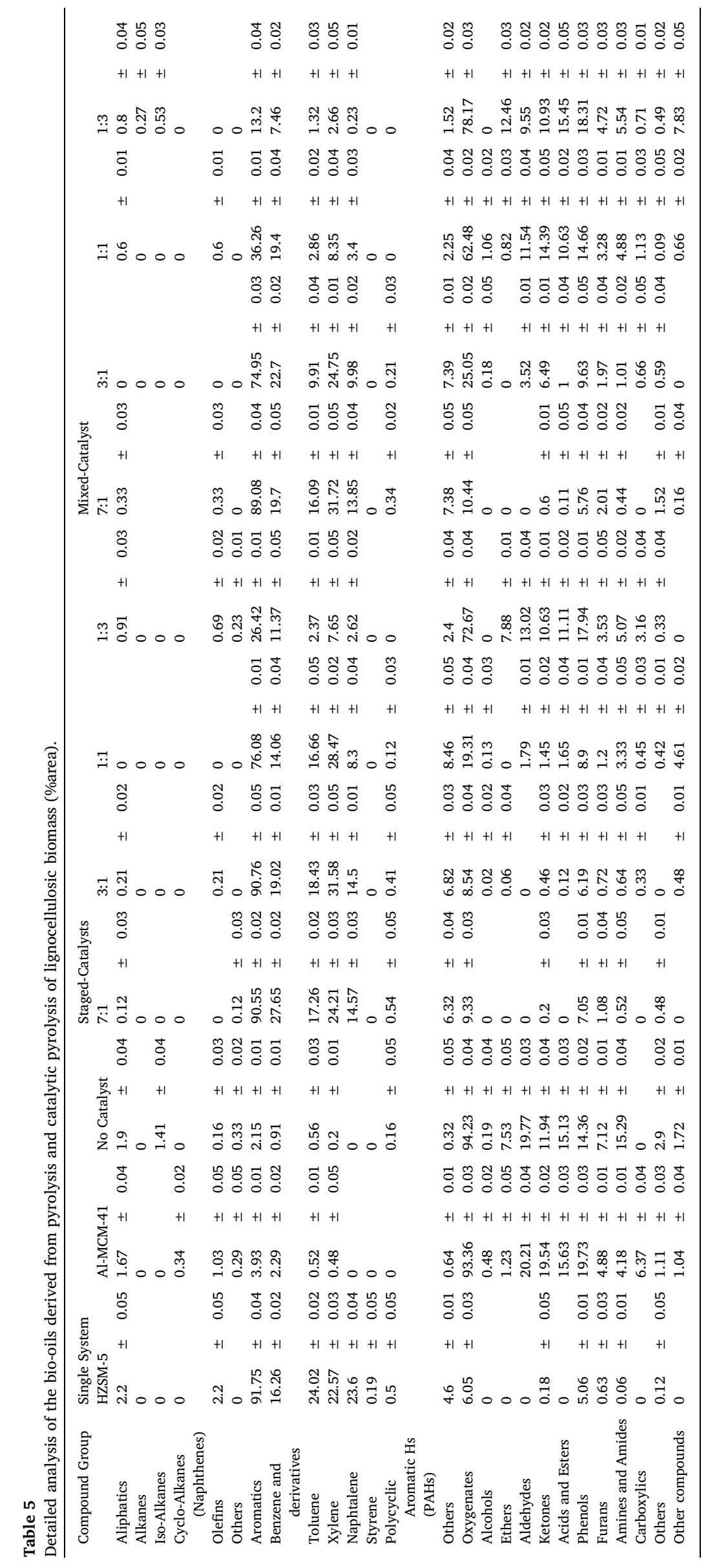


Table 6

Favourable and unfavourable compounds in the bio-oils from pyrolysis and catalytic pyrolysis of lignocellulosic biomass (\%area).

\begin{tabular}{lll}
\hline \multirow{2}{*}{ Systems } & \multicolumn{2}{l}{ Compound Group } \\
\cline { 2 - 3 } & Favourable compound & Unfavourable compound \\
\hline No Catalyst & 25.25 & 74.75 \\
HZSM-5 & 70.93 & 29.07 \\
Al-MCM-41 & 30.05 & 69.95 \\
Staged-Catalyst (HZSM-5:Al-MCM-41) & \\
7:1 & 77.36 & 22.64 \\
$3: 1$ & 76.20 & 23.82 \\
$1: 1$ & 69.42 & 30.58 \\
$1: 3$ & 43.78 & 56.22 \\
Mixed-Catalyst (HZSM-5:Al-MCM-41) & \\
$7: 1$ & 75.60 & 24.40 \\
$3: 1$ & 69.13 & 30.87 \\
$1: 1$ & 50.21 & 49.79 \\
$1: 3$ & 35.28 & 64.72 \\
\hline
\end{tabular}

with a staged-catalyst system with HZSM-5:Al-MCM-41 ratio of 3:1 and 7:1, which give 5.25 and $6.43 \%$ higher than with single HZSM-5. These findings suggest that the synergistic effects between HZSM-5 and AlMCM-41 may occur in the staged-catalyst and mixed-catalyst system.

However, the low amount of favourable products in mixed-catalysts systems was observed compared to the amount in the staged-catalysts system. This is due to the possibility that a certain amount of large molecules oxygenates only enter the pores of Al-MCM-41 without being converted further by HZSM- 5 . Consequently, the cracking of oxygenates with the mixed-catalyst system was less effective compared to with staged-catalyst system.

In terms of gasoline-range chemicals, it can be seen from Table 7 that the use of HZSM-5 led to the formation of gasoline-range chemicals, whereas Al-MCM-41 promoted the production of C1-C4 as well as > C12 fractions. In the staged-catalysts systems, increasing the content of HZSM- 5 in the catalyst systems enhanced the yields of gasoline-range chemicals and decreased C1-C4 as well as > C12 yields, whereas no regularity was observed in the mixed-catalysts systems. No certain pathways for oxygenate molecules to catalytically react is a reason of irregularity in the results from mixed-catalysts systems.

The result is in the lines of earlier literature [45] that found AlMCM-41 was not as effective at deoxygenating the liquid phase as HZSM-5. Instead, Al-MCM-41 gave more phenols than simple aromatics. The use of HZSM- 5 was also successful at the reduction of acids and carbonyls which have an influence on the corrosive nature and stability of the bio-oil. However, higher deoxygenation and improvement with HZSM-5 was at the costs of a lower yield of organic liquid,

Table 7

Distribution of gasoline-range chemicals (C5-C12) in the bio-oils from pyrolysis and catalytic pyrolysis of lignocellulosic biomass (\%area).

\begin{tabular}{llll}
\hline \multirow{2}{*}{ Systems } & \multicolumn{2}{l}{ Carbon range } & \\
\cline { 2 - 4 } & C1-C4 & $\begin{array}{l}\text { C5-C12 } \\
\text { (Gasoline-range) }\end{array}$ & $>$ C12 \\
& & 69.78 & 7.38 \\
No Catalyst & 22.84 & 98.64 & 1.36 \\
HZSM-5 & 0.00 & 66.74 & 15.03 \\
Al-MCM-41 & 18.23 & & \\
Staged-Catalyst (HZSM-5:Al-MCM-41) & 98.52 & 1.48 \\
7:1 & 0,00 & 97.89 & 1.95 \\
$3: 1$ & 0.16 & 96.01 & 1.26 \\
$1: 1$ & 2.74 & 84.50 & 1.17 \\
$1: 3$ & 14.33 & & 1.20 \\
Mixed-Catalyst (HZSM-5:Al-MCM-41) & 98.80 & 5.58 \\
$7: 1$ & 0.00 & 92.50 & 8.17 \\
$3: 1$ & 1.91 & 78.55 & 2.71 \\
$1: 1$ & 13.27 & 80.90 & \\
$1: 3$ & 16.39 & & \\
\hline
\end{tabular}

Table 8

Product yields (wt.\%) from catalytic pyrolysis of lignocellulosic biomass with staged-catalyst 3:1 of HZSM-5:Al-MCM-41 over different catalytic pyrolysis temperatures with 95\% mean Confidence Intervals (CIs).

\begin{tabular}{llll}
\hline \multirow{2}{*}{ Product yield } & \multicolumn{2}{l}{ Temperature $\left({ }^{\circ} \mathrm{C}\right)$} & \\
\cline { 2 - 4 } & 400 & 500 & 600 \\
\hline Oil & $14.67 \pm 0.01$ & $10.31 \pm 0.01$ & $9.46 \pm 0.01$ \\
Water & $43.20 \pm 0.02$ & $41.58 \pm 0.03$ & $39.43 \pm 0.01$ \\
Gas & $15.47 \pm 0.04$ & $22.19 \pm 0.04$ & $26.22 \pm 0.04$ \\
Char & $26.66 \pm 0.04$ & $25.92 \pm 0.04$ & $24.89 \pm 0.03$ \\
Mass Balance & $94.08 \pm 0.05$ & $90.95 \pm 0.03$ & $93.57 \pm 0.03$ \\
\hline
\end{tabular}

compared with Al-MCM-41. When the bio-oil from catalytic pyrolysis is targeted as a transportation fuel, the production of liquid fractions is important. Thus, catalytic pyrolysis with staged-catalysts and mixedcatalysts could be applied to produce high-quality bio-oil.

The current findings suggest that the best compromise to obtain biooil with more than $75 \%$ of favourable fractions in the Oil Liquid Products (OLP), and low TAN as well as low amount of acids and carbonyls, were using staged-catalysts with the HZSM-5:Al-MCM-41 ratio of either $3: 1$ or $7: 1$ since there were insignificant differences between the liquid products from both systems.

\subsection{The Influence of the Reaction Temperature on the Conversion}

The influence of reaction temperature was investigated on the product distribution of the suggested system to produce high-quality bio-oil, in this case, staged-catalyst with HZSM-5:Al-MCM-41 of 3:1. The following temperatures were examined: 400,500 , and $600{ }^{\circ} \mathrm{C}$.

\subsubsection{Product yields}

Table 8 shows the influence of the catalyst temperature on the product yields for a catalytic pyrolysis of lignocellulosic biomass when using staged catalysts consisting of HZSM-5 and Al-MCM-41 with a ratio of 3:1. The measurements for each case were found to be statistically identical. The significant differences in the production of oil, water, gas, and char were also encountered among all systems.

In this study, increasing the reaction temperature caused a decrease in liquid fractions (OLP and water content) and increased gaseous products. The water content of the bio-oils decreased to $39.43 \mathrm{wt} \%$ at temperature of $600{ }^{\circ} \mathrm{C}$ from $43.20 \mathrm{wt} . \%$ at $400{ }^{\circ} \mathrm{C}$ and $41.58 \mathrm{wt} \%$ at $500{ }^{\circ} \mathrm{C}$, which indicates that the OLP decreased from $14.67 \mathrm{wt} \%$ at temperature of $400{ }^{\circ} \mathrm{C}$ to 10.31 wt. $\%$ at $500{ }^{\circ} \mathrm{C}$ and 9.46 wt. $\%$ at $600{ }^{\circ} \mathrm{C}$. As for the gaseous products, it showed an increasing trend from $15.47 \mathrm{wt} . \%$ at $400{ }^{\circ} \mathrm{C}$ to $22.19 \mathrm{wt} . \%$ and $26.22 \mathrm{wt} . \%$ at $500{ }^{\circ} \mathrm{C}$ and $600{ }^{\circ} \mathrm{C}$, respectively. This finding suggests that the increasing temperature in the catalytic pyrolysis of lignocellulosic biomass with staged-catalyst HZSM:5:Al-MCM-41 ratio of 3:1 enhanced the deoxygenation process and gave off high non-condensable gases. Thus, less OLP was observed with the increase in temperature. Table 9 shows the influence of temperatures on gas composition from pyrolysis and catalytic pyrolysis of lignocellulosic biomass. The hydrogen, $\mathrm{CO}, \mathrm{CO} 2$, and hydrocarbon gases increased as the temperature was increased.

Fig. 4 shows the Total Acid Number (TAN) of bio-oils from catalytic pyrolysis with staged-catalyst HZSM-5:Al-MCM-41 ratio of 3:1 at different temperatures. TAN of bio-oil decreased from $84.29 \mathrm{mg}-\mathrm{KOH} / \mathrm{g}$ at a temperature of $400{ }^{\circ} \mathrm{C}$ to $44.70 \mathrm{mg}-\mathrm{KOH} / \mathrm{g}$ at $500{ }^{\circ} \mathrm{C}$, then further decreased to $32.85 \mathrm{mg}-\mathrm{KOH} / \mathrm{g}$ at a temperature of $600{ }^{\circ} \mathrm{C}$. On the other hand, as seen in Table 10, the acids and carbonyls (aldehydes and ketones) content in the bio-oils from the run at $400{ }^{\circ} \mathrm{C}$ was $1.19 \%$, and then it decreased to $0.58 \%$ and $0.31 \%$ at $500{ }^{\circ} \mathrm{C}$ and $600{ }^{\circ} \mathrm{C}$, respectively. This study indicates that acids and carbonyls highly influence the acidity of bio-oil. Thus, the TAN reached the lowest point and underwent high deoxygenation at the temperature of $600{ }^{\circ} \mathrm{C}$. However, TAN 
Table 9

The influence of temperature on gas composition from pyrolysis and catalytic pyrolysis of lignocellulosic biomass (wt.\%).

\begin{tabular}{llll}
\hline Gas & \multicolumn{2}{l}{ Temperature $\left({ }^{\circ} \mathrm{C}\right)$} & \\
\cline { 2 - 4 } & 400 & 500 & 600 \\
\hline $\mathrm{H}_{2}$ & $0.37 \pm 0.05$ & $0.52 \pm 0.04$ & $0.76 \pm 0.03$ \\
$\mathrm{CO}$ & $3.55 \pm 0.02$ & $5.07 \pm 0.04$ & $6.12 \pm 0.01$ \\
$\mathrm{CO}$ & $9.50 \pm 0.03$ & $13.37 \pm 0.04$ & $14.21 \pm 0.04$ \\
$\mathrm{CH}_{4}$ & $0.76 \pm 0.05$ & $0.83 \pm 0.05$ & $1.34 \pm 0.04$ \\
$\mathrm{C}_{2} \mathrm{H}_{4}$ & $0.41 \pm 0.02$ & $0.73 \pm 0.01$ & $0.88 \pm 0.01$ \\
$\mathrm{C}_{2} \mathrm{H}_{6}$ & $0.22 \pm 0.01$ & $0.48 \pm 0.01$ & $0.98 \pm 0.04$ \\
$\mathrm{C}_{3} \mathrm{H}_{6}$ & $0.43 \pm 0.04$ & $0.73 \pm 0.01$ & $1.16 \pm 0.02$ \\
$\mathrm{C}_{3} \mathrm{H}_{8}$ & $0.22 \pm 0.03$ & $0.46 \pm 0.04$ & $0.77 \pm 0.03$ \\
Total & $15.47 \pm 0.04$ & $22.19 \pm 0.04$ & $26.22 \pm 0.04$ \\
\hline
\end{tabular}

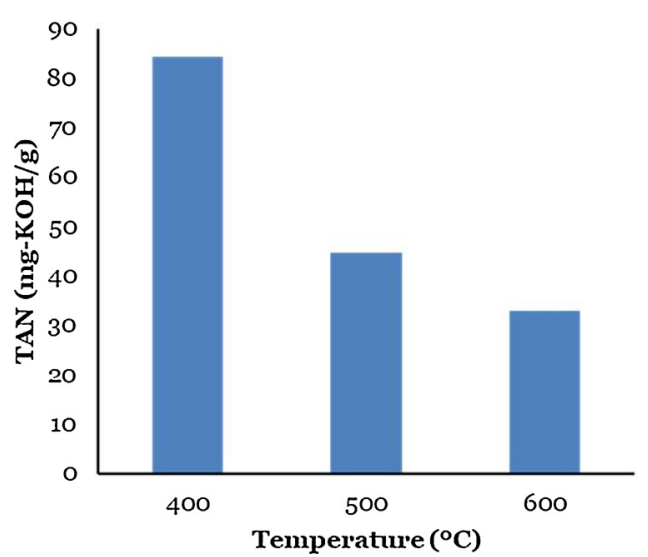

Fig. 4. Total Acid Number (TAN) of bio-oils from catalytic pyrolysis with staged-catalyst HZSM-5:Al-MCM-41 ratio of 3:1 at different temperatures.

from this study was still too high for further processing in a petroleum refinery.

\subsubsection{Analysis of catalytic pyrolysis oil at different temperatures}

The highest aromatics content of $93.13 \%$ was achieved from the run at $600{ }^{\circ} \mathrm{C}$, as seen in Table 10 . The temperature of the catalyst in catalytic pyrolysis of biomass affects the rates of thermal and catalytic reactions such as cracking, dehydration, decarbonylation, decarboxylation, and aromatisation [46], thus affecting the selectivity of aromatic hydrocarbons and the deoxygenation pathways. Increasing catalyst temperature leads to high selectivity and yields of aromatic hydrocarbons [46,47].

As shown in Table 11, the highest amount of favourable compound was obtained at a temperature of $500{ }^{\circ} \mathrm{C}$, amounting to $76.20 \%$. The yield of phenols also reached the highest point at $500^{\circ} \mathrm{C}$, while at $600{ }^{\circ} \mathrm{C}$ the high production of xylene and naphthalene was detected. This finding suggests that catalytic pyrolysis of lignocellulosic biomass with staged-catalysts HZSM-5:Al-MCM-41 ratio of 3:1 was effective to produce favourable compound at a temperature of $500{ }^{\circ} \mathrm{C}$.

In terms of gasoline-range chemicals, it can be seen from Table 12 that the highest gasoline-range chemical was achieved for the run at $500^{\circ} \mathrm{C}$. It can also be seen that the low temperature, in this case at $400{ }^{\circ} \mathrm{C}$, the oil products consisted $\mathrm{C} 1-\mathrm{C} 4$ and $>\mathrm{C} 12$ fractions, amounting to $2.12 \%$ and $3.56 \%$, respectively, while at the high temperature of $600{ }^{\circ} \mathrm{C}$, the staged-catalyst led to the light carbon molecule formation. As for the run at $500{ }^{\circ} \mathrm{C}$, most of the fractions was in gasoline-range chemicals, $0.16 \%$ of $\mathrm{C} 1-\mathrm{C} 4$, and $1.95 \%$ of $>\mathrm{C} 12$ fractions.

The results of the present study suggest that the effective temperature for catalytic pyrolysis of lignocellulosic biomass with staged-catalyst HZSM-5:Al-MCM-41 ratio of 3:1 to produce bio-oil with more than $75 \%$ of favourable fractions in the OLP, low acidity, high
Table 10

Detailed analysis of the bio-oils derived from catalytic pyrolysis of lignocellulosic biomass using staged-catalysts with different reaction temperatures (\%area).

\begin{tabular}{|c|c|c|c|c|c|c|c|c|c|}
\hline \multirow{3}{*}{$\begin{array}{l}\text { Compound Group } \\
\text { Aliphatics }\end{array}$} & \multicolumn{9}{|c|}{ Temperature $\left({ }^{\circ} \mathrm{C}\right)$} \\
\hline & \multicolumn{3}{|l|}{400} & \multicolumn{3}{|l|}{500} & \multicolumn{3}{|l|}{600} \\
\hline & 0.00 & & & 0.21 & \pm & 0.05 & 0.00 & & \\
\hline Alkanes & 0.00 & & & 0.00 & & & 0.00 & & \\
\hline Iso-Alkanes & 0.00 & & & 0.00 & & & 0.00 & & \\
\hline $\begin{array}{l}\text { Cyclo-Alkanes } \\
\text { (Naphthenes) }\end{array}$ & 0.00 & & & 0.00 & & & 0.00 & & \\
\hline Olefins & 0.00 & & & 0.21 & \pm & 0.05 & 0.00 & & \\
\hline Others & 0.00 & & & 0.00 & & & 0.00 & & \\
\hline Aromatics & 82.48 & \pm & 0.05 & 90.76 & \pm & 0.04 & 93.13 & \pm & 0.05 \\
\hline $\begin{array}{l}\text { Benzene and } \\
\text { derivatives }\end{array}$ & 24.94 & \pm & 0.05 & 19.02 & \pm & 0.05 & 17.39 & \pm & 0.05 \\
\hline Toluene & 20.49 & \pm & 0.01 & 18.43 & \pm & 0.02 & 15.03 & \pm & 0.02 \\
\hline Xylene & 22.87 & \pm & 0.02 & 31.58 & \pm & 0.05 & 37.22 & \pm & 0.05 \\
\hline Naphtalene & 11.29 & \pm & 0.05 & 14.50 & \pm & 0.03 & 20.44 & \pm & 0.03 \\
\hline Styrene & 0.00 & & & 0.00 & & & 0.00 & & \\
\hline $\begin{array}{c}\text { Polycyclic Aromatic } \\
\text { Hs (PAHs) }\end{array}$ & 0.00 & & & 0.41 & \pm & 0.04 & 0.00 & & \\
\hline Others & 7.89 & \pm & 0.05 & 6.82 & \pm & 0.04 & 3.30 & \pm & 0.01 \\
\hline Oxygenates & 14.58 & \pm & 0.05 & 8.57 & \pm & 0.04 & 6.65 & \pm & 0.03 \\
\hline Alcohols & 0.49 & \pm & 0.04 & 0.02 & \pm & 0.04 & 0.00 & & \\
\hline Ethers & 0.00 & & & 0.06 & \pm & 0.01 & 0.00 & & \\
\hline Aldehydes & 0.00 & & & 0.00 & & & 0.00 & & \\
\hline Ketones & 0.84 & \pm & 0.01 & 0.46 & \pm & 0.01 & 0.20 & \pm & 0.05 \\
\hline Acids and Esters & 0.35 & \pm & 0.05 & 0.12 & \pm & 0.05 & 0.11 & \pm & 0.02 \\
\hline Phenols & 3.25 & \pm & 0.04 & 6.21 & \pm & 0.05 & 4.79 & \pm & 0.02 \\
\hline Furans & 1.24 & \pm & 0.03 & 0.72 & \pm & 0.05 & 0.38 & \pm & 0.04 \\
\hline Amines and Amides & 3.14 & \pm & 0.04 & 0.64 & \pm & 0.05 & 0.38 & \pm & 0.03 \\
\hline Carboxylics & 0.00 & & & 0.33 & \pm & 0.03 & 0.00 & & \\
\hline Others & 0.28 & \pm & 0.05 & 0.00 & & & 0.79 & \pm & 0.04 \\
\hline Other compounds & 2.94 & \pm & 0.02 & 0.48 & \pm & 0.03 & 0.22 & \pm & 0.03 \\
\hline
\end{tabular}

Table 11

Favourable and unfavourable compounds of bio-oils from catalytic pyrolysis of lignocellulosic biomass at different temperatures (\%area).

\begin{tabular}{lll}
\hline Temperature $\left({ }^{\circ} \mathrm{C}\right)$ & Compound Group & \\
\cline { 2 - 3 } & Favourable compound & Unfavourable compound \\
\hline 400 & 73.27 & 26.73 \\
500 & 76.20 & 23.82 \\
600 & 74.81 & 25.44 \\
\hline
\end{tabular}

Table 12

Distribution of gasoline-range chemicals (C5-C12) in the bio-oil from catalytic pyrolysis of lignocellulosic biomass with different temperatures (\%area).

\begin{tabular}{llll}
\hline Temperature $\left({ }^{\circ} \mathrm{C}\right)$ & \multicolumn{2}{l}{ Carbon range } & \\
\cline { 2 - 4 } & C1-C4 & $\begin{array}{l}\text { C5-C12 } \\
\text { (Gasoline-range) }\end{array}$ & $>\mathrm{C} 12$ \\
& & 94.32 & 3.56 \\
400 & 2.12 & 97.89 & 1.95 \\
600 & 0.16 & 96.05 & 1.06 \\
\hline
\end{tabular}

deoxygenation, as well as high gasoline-range production, were at $500{ }^{\circ} \mathrm{C}$.

\section{Conclusion}

A catalytic pyrolysis of lignocellulosic biomass was carried out using a fixed bed reactor by employing staged catalysts and mixed catalysts consisting of HZSM-5 and Al-MCM-41 at different temperatures, to produce a high quality of bio-oil with a high yield of gasoline-range chemicals. 
The more specific conclusions from the study can be summarized as follows:

1 The favourable compound resulted from catalytic pyrolysis using mixed-catalyst with HZSM-5:Al-MCM-41 ratio of 7:1 as well as using staged-catalyst with HZSM-5:Al-MCM-41 ratio of 3:1 and 7:1 were 4.67-6.43\% higher than it from catalytic pyrolysis using single HZSM-5. The synergistic effects of HZSM-5 and Al-MCM-41 may occur in the staged-catalyst and mixed-catalyst system. Yet, the number of favourable products in the mixed-catalyst system was lower than in the staged-catalyst system, due to the possibility that a certain amount of large molecules oxygenates only enter the pores of Al-MCM-41 without being converted further by HZSM-5. Consequently, the cracking of oxygenates with the mixed-catalyst system was less effective compared to with staged-catalyst system.

2 The staged-catalysts with the HZSM-5:Al-MCM-41 ratio of either 3:1 or $7: 1$ was the best compromise to obtain $10.65-11.08 \mathrm{wt} . \%$ of biooil with $76.20-77.36 \%$ of favourable fractions, water content of 41.97-42.45 wt.\%, low TAN of 43.01-44.70 mg-KOH/g, and 97.89$98-52 \%$ of gasoline-range chemicals were using, compared to using single catalysts or mixed-catalyst system.

3 The optimum temperature for catalytic pyrolysis of lignocellulosic biomass with staged-catalyst HZSM-5:Al-MCM-41 ratio of 3:1 to obtain 11.08 wt.\% of bio-oil with $76.20 \%$ of favourable fractions, $41.97 \mathrm{wt} . \%$ of water content, low TAN of $43.01 \mathrm{mg}-\mathrm{KOH} / \mathrm{g}$, high deoxygenation, as well as high gasoline-range production of $97.89 \%$, were at $500{ }^{\circ} \mathrm{C}$.

\section{Acknowledgment}

The financial support from the Swedish Energy AgencyEnergimydigheten under the ERA-NET Bioenergy program No. 43911-1 is high acknowledgment.

\section{References}

[1] U. S. Energy Information Administration, EIA Projects World Energy Consumption Will Increase $56 \%$ by 2040 , IEO2013, 2013 (Accessed 1 September 2017), https:// www.eia.gov/todayinenergy/detail.php?id =12251.

[2] C. Liu, H. Wang, A.M. Karim, J. Sun, Y. Wang, Catalytic fast pyrolysis of lignocellulosic biomass, Chem. Soc. Rev. 43 (2014) 7594-7623, https://doi.org/10. 1039/C3CS60414D.

[3] A. Aho, N. Kumar, K. Eränen, T. Salmi, M. Hupa, D.Y. Murzin, Catalytic pyrolysis of biomass in a fluidized bed reactor: influence of the acidity of H-Beta zeolite, IChemE. 85 (2007) 473-480, https://doi.org/10.1205/psep07012.

[4] M. Asadieraghi, W.M. Ashri Wan Daud, H.F. Abbas, Heterogeneous catalysts for advanced bio-fuel production through catalytic biomass pyrolysis vapor upgrading: a review, RSC Adv 5 (2015) 22234-22255 https://doi.org/10.1039/C5RA00762C.

[5] L. Bosong, L. Wei, Z. Qi, W. Tiejun, M. Longlong, Pyrolysis and catalytic upgrading of pine wood in a combination of auger reactor and fixed bed, FUEL 129 (2014) 61-67, https://doi.org/10.1016/j.fuel.2014.03.043.

[6] E. Antonakou, A. Lappas, M.H. Nilsen, A. Bouzga, M. Sto, Evaluation of various types of Al-MCM-41 materials as catalysts in biomass pyrolysis for the production of bio-fuels and chemicals, FUEL 85 (2006) 2202-2212, https://doi.org/10.1016/j. fuel.2006.03.021.

[7] J. Adam, E. Antonakou, A. Lappas, M. Stöcker, M.H. Nilsen, A. Bouzga, J.E. Hustad, G. Øye, In situ catalytic upgrading of biomass derived fast pyrolysis vapours in a fixed bed reactor using mesoporous materials, Microporous Mesoporous Mater. 96 (2006) 93-101, https://doi.org/10.1016/j.micromeso.2006.06.021.

[8] D. Bose, D. Arora, A. Mekala, On the effect of hydrothermal pretreatment of biomass and catalytic conversion mechanism in pyrolysis process with a review of flash pyrolysis of lignocellulosic biomass using effective catalyst, World Sci. News 4 (2015) 140-152.

[9] A.V. Bridgwater, Upgrading biomass fast pyrolysis liquids, Environ. Prog. Sustain. Energy 31 (2012) 261-268, https://doi.org/10.1002/ep.

[10] A.G. Gayubo, A.T. Aguayo, A. Atutxa, R. Aguado, J. Bilbao, Transformation of oxygenate components of biomass pyrolysis oil on a HZSM-5 Zeolite. I. Alcohols and Phenols, Ind. Eng. Chem. Res. 43 (2004) 2610-2618, https://doi.org/10.1021/ ie0307910.

[11] S. Jones, C. Valkenburg, C. Walton, D. Elliott, Production of Gasoline and Diesel From Biomass Via Fast Pyrolysis, Hydrotreating and Hydrocracking: a Design Case, United States of America, n.d. (2018) https://www.pnnl.gov/main/publications/ external/technical_reports/PNNL-18284.pdf.

[12] A.V. Bridgwater, Review of fast pyrolysis of biomass and product upgrading, Biomass Bioenergy 38 (2011) 68-94, https://doi.org/10.1016/j.biombioe.2011.01.
048.

[13] Q. Zhang, J. Chang, T. Wang, Y. Xu, Review of biomass pyrolysis oil properties and upgrading research, Energy Convers. Manag. 48 (2007) 87-92, https://doi.org/10. 1016/j.enconman.2006.05.010.

[14] D.A. Bulushev, J.R.H. Ross, Catalysis for conversion of biomass to fuels via pyrolysis and gasification: a review, Catal. Today 171 (2011) 1-13, https://doi.org/10.1016/ j.cattod.2011.02.005.

[15] J. Jae, G.A. Tompsett, A.J. Foster, K.D. Hammond, S.M. Auerbach, R.F. Lobo, G.W. Huber, Investigation into the shape selectivity of zeolite catalysts for biomass conversion, J. Catal. 279 (2011) 257-268, https://doi.org/10.1016/j.jcat.2011.01. 019.

[16] Y. Yu, X. Li, L. Su, Y. Zhang, Y. Wang, H. Zhang, The role of shape selectivity in catalytic fast pyrolysis of lignin with zeolite catalysts, Appl. Catal. A Gen. 447-448 (2012) 115-123, https://doi.org/10.1016/j.apcata.2012.09.012.

[17] V. Umamaheswari, Isopropylation of m-Cresol over mesoporous Al-MCM-41 molecular sieves, J. Catal. 210 (2002) 367-374, https://doi.org/10.1006/jcat.2002. 3709.

[18] W. SONG, X. LIU, T. JING, Q. DENG, Characterization and catalytic properties of AlMCM-41 mesoporous materials grafted with tributyltin chloride, Chinese J. Chem. Eng. 20 (2012) 900-905, https://doi.org/10.1016/S1004-9541(12)60416-9.

[19] Q. Wei, L. Liu, Z. Nie, Z. Chen, J. Zou, Preparation and characterization of mesoporous Al-MCM-41 layers deposited on FeCrAl metallic foils by an in-situ hydrothermal method, J. Wuhan Univ. Technol. Sci. Ed. 24 (2009) 1-4, https://doi.org/ 10.1007/s11595-009-1001-3.

[20] A.C. Carmo, L.K.C. de Souza, C.E.F. da Costa, E. Longo, J.R. Zamian, G.N. da Rocha Filho, Production of biodiesel by esterification of palmitic acid over mesoporous aluminosilicate Al-MCM-41, Fuel 88 (2009) 461-468, https://doi.org/10.1016/j. fuel.2008.10.007.

[21] E.F. Iliopoulou, E.V. Antonakou, S.A. Karakoulia, I.A. Vasalos, A.A. Lappas, K.S. Triantafyllidis, Catalytic conversion of biomass pyrolysis products by mesoporous materials : effect of steam stability and acidity of Al-MCM-41 catalysts, Chem. Eng. J. 134 (2007) 51-57, https://doi.org/10.1016/j.cej.2007.03.066.

[22] S. Kelkar, C.M. Saffron, K. Andreassi, Z. Li, A. Murkute, D.J. Miller, T.J. Pinnavaia, R.M. Kriegel, Appl. Catal. B 174-175 (2015) 85-95, https://doi.org/10.1016/j apcatb.2015.02.020.

[23] S. Wan, Y. Wang, A review on ex situ catalytic fast pyrolysis of biomass, PMSE Preprints 8 (2014) 280-294, https://doi.org/10.1007/s11705-014-1436-8.

[24] T.L. Marker, J.A. Petri, Gasoline and Diesel Production from Pyrolytic Lignin Produced from Pyrolysis of Cellulosic Waste, US 7,578,927 B2, 2009. https:// patentimages.storage.googleapis.com/21/5f/7a/e2225c2b39b790/US7578927. pdf.

[25] J.D. Adjaye, S.P.R. Katikaneni, N.N. Bakhshi, Catalytic conversion of a biofuel to hydrocarbons : effect of mixtures of HZSM-5 and silica-alumina catalysts on product distribution, Fuel Process. Technol. 48 (1996) 115-143.

[26] H. Zhang, R. Xiao, B. Jin, G. Xiao, R. Chen, Biomass catalytic pyrolysis to produce olefins and aromatics with a physically mixed catalyst, Bioresour. Technol. 140 (2013) 256-262, https://doi.org/10.1016/j.biortech.2013.04.094.

[27] H. Zhang, J. Zheng, R. Xiao, Y. Jia, D. Shen, B. Jin, G. Xiao, Study on pyrolysis of pine sawdust with solid base and acid mixed catalysts by thermogravimetry-fourier transform infrared spectroscopy and pyrolysis-gas chromatography/mass spectrometry, Energy Fuels 28 (2014) 4294-4299, https://doi.org/10.1021/ef500176w.

[28] D.K. Ratnasari, M.A. Nahil, P.T. Williams, Catalytic pyrolysis of waste plastics using staged catalysis for production of gasoline range hydrocarbon oils, J. Anal. Appl. Pyrolysis 124 (2017) 631-637, https://doi.org/10.1016/j.jaap.2016.12.027.

[29] D.J.M. Hayes, Biomass Composition and Its Relevance to Biorefining, \&copy; 2013 Elsevier B.V. All Rights Reserved. (2013), https://doi.org/10.1016/B978-0-44456330-9.00002-4.

[30] Mettler Toledo, Good Titration Practice in Karl Fischer Titration, (2018) https:// www.mt.com/dam/non-indexed/po/ana/titration/51725145B_V10.11_GTP_KF Titr_HB_Complet.pdf.

[31] Mettler Toledo, Thermometric Titration of Acid Number According to ASTM D8045, (2018) https://www.mt.com/dam/MT-NA/pdf/ ThermometricTitrationofAcidNumber WhitePaper pdf.

[32] A. Imran, E. Bramer, K. Seshan, G. Brem, Catalytic flash pyrolysis of biomass using different types of zeolite and online vapor fractionation, Energies 9 (2016) 187, https://doi.org/10.3390/en9030187.

[33] A. Atutxa, R. Aguado, A.G. Gayubo, M. Olazar, J. Bilbao, Kinetic description of the catalytic pyrolysis of biomass in a conical spouted bed reactor, Energy Fuels 19 (2005) 765-774, https://doi.org/10.1021/ef040070h.

[34] S. Du, Y. Sun, D.P. Gamliel, J.A. Valla, G.M. Bollas, Catalytic pyrolysis of miscanthus $\times$ giganteus in a spouted bed reactor, Bioresour. Technol. 169 (2014) 188-197, https://doi.org/10.1016/j.biortech.2014.06.104.

[35] H. Zhang, R. Xiao, H. Huang, G. Xiao, Comparison of non-catalytic and catalytic fast pyrolysis of corncob in a fluidized bed reactor, Bioresour. Technol. 100 (2009) 1428-1434, https://doi.org/10.1016/j.biortech.2008.08.031.

[36] Y. Zheng, L. Tao, X. Yang, Y. Huang, C. Liu, J. Gu, Z. Zheng, Effect of acidity and manner of addition of HZSM-5 catalyst on the aromatic products during catalytic upgrading of biomass pyrolysis, Bioresources 12 (2017) 8286-8305, https://doi. org/10.15376/biores.12.4.8286-8305.

[37] M.C. Samolada, A. Papafotica, I.A. Vasalos, Catalyst evaluation for catalytic biomass pyrolysis, Energy Fuels 14 (2000) 1161-1167.

[38] Y. WANG, Z. CHU, B. QIU, C. LIU, Y. ZHANG, Removal of naphthenic acids from a vacuum fraction oil with an ammonia solution of ethylene glycol, Fuel 85 (2006) 2489-2493, https://doi.org/10.1016/j.fuel.2006.04.032.

[39] L. Moens, S.K. Black, M.D. Myers, S. Czernik, Study of the neutralization and stabilization of a mixed hardwood bio-oil, Energy Fuels 23 (2009) 2695-2699, https:// 
doi.org/10.1021/ef8009266.

$40]$ A. Oasmaa, S. Czernik, Fuel oil quality of biomass pyrolysis oils - state of the art for the end users, Energy Fuels 13 (1999) 914-921, https://doi.org/10.1021/ ef980272b.

[41] A. Oasmaa, D.C. Elliott, J. Korhonen, Acidity of biomass fast pyrolysis bio-oils, Energy Fuels 24 (2010) 6548-6554, https://doi.org/10.1021/ef100935r.

[42] C.A. Mullen, A.A. Boateng, Production of aromatic hydrocarbons via catalytic pyrolysis of biomass over Fe-Modified HZSM-5 zeolites, ACS Sustain. Chem. Eng. 3 (2015) 1623-1631, https://doi.org/10.1021/acssuschemeng.5b00335.

[43] A. Pattiya, J.O. Titiloye, A.V. Bridgwater, Fast pyrolysis of cassava rhizome in the presence of catalysts, J. Anal. Appl. Pyrolysis 81 (2008) 72-79, https://doi.org/10. 1016/j.jaap.2007.09.002

[44] J. Adam, M. Blazso, E. Meszaros, M. Stocker, M. Nilsen, A. Bouzga, J. Hustad,
M. Gronli, G. Oye, Pyrolysis of biomass in the presence of Al-MCM-41 type catalysts, Fuel (2005), https://doi.org/10.1016/j.fuel.2005.02.006.

[45] M.A. Jackson, D.L. Compton, A.A. Boateng, Screening heterogeneous catalysts for the pyrolysis of lignin, J. Anal. Appl. Pyrolysis 85 (2009) 226-230, https://doi.org/ 10.1016/j.jaap.2008.09.016.

[46] X. Zhang, H. Lei, L. Zhu, M. Qian, J.C. Chan, X. Zhu, Y. Liu, G. Yadavalli, D. Yan, L. Wang, Q. Bu, Y. Wei, J. Wu, S. Chen, Development of a catalytically green route from diverse lignocellulosic biomasses to high-density cycloalkanes for jet fuels, Catal. Sci. Technol. 6 (2016) 4210-4220, https://doi.org/10.1039/C5CY01623A.

[47] G. Zhou, P.A. Jensen, D.M. Le, N.O. Knudsen, A.D. Jensen, Direct upgrading of fast pyrolysis lignin vapor over the HZSM-5 catalyst, Green Chem. 18 (2016) 1965-1975, https://doi.org/10.1039/C5GC01976A. 
Corrigendum

Corrigendum to <'Two-stage ex-situ catalytic pyrolysis of lignocellulose for the production of gasoline-range chemicals' $>$ $<$ Journal of Analytical and Applied Pyrolysis, Volume 134, p. 454-464]>

$<$ Devy K. Ratnasari, Weihong Yang, Pär G. Jönsson> $<$ KTH Royal Institute of Technology, Department of Material Science and Engineering, Brinellvägen 23,10044 Stockholm, Sweden>

Text to be included in the corrigendum:

In subpart 2.2 Experimental Reactor, the ratio of sample to catalysts was incorrectly written as 1:2 but should have been 1:1. The sample (10 g) was used and a catalyst bed mass should be corrected as $10 \mathrm{~g}$.

DOI of original article: $<10.1016 /$ j.jaap.2018.07.012 $>$

$<$ Devy K. Ratnasari $>$

$<$ dkra@kth.se> 